\title{
GESTÃO PARTICIPATIVA DA EDUCAÇÃO: POLÍTICA NEOLIBERAL OU AUTONOMIA ADMINISTRATIVA?
}

\author{
Valdecir Soligo \\ Marinez Gasparin Soligo \\ Adrian Alvarez Estrada \\ Universidade Estadual do Oeste do Paraná (Unioeste), Cascavel, Paraná, \\ Brasil
}

\begin{abstract}
RESUMO: Este estudo é parte de um projeto em que discutimos o perfil dos gestores de escolas públicas do Oeste do Paraná. Objetivamos apresentar e debater os encaminhamentos da gestão participativa desenvolvida nas políticas educacionais do estado do Paraná. A pesquisa é de cunho qualitativo, pautada em revisão bibliográfica e análise de dados oriundos dos questionários contextuais da Prova Brasil respondidos pelos gestores de escolas estaduais. Como resultados, temos apontamentos quanto à redução do papel do Estado na educação, descentralizando parte da gestão financeira das escolas e mantendo a centralidade no controle dos processos.
\end{abstract}

Palavras-chave: Gestão participativa. Desresponsabilização. Neoliberalismo. Gestão escolar.

\section{PARA COMEÇO DE CONVERSA: O NEOLIBERALISMO NA GESTÃO EDUCACIONAL}

Este estudo é parte de uma pesquisa mais ampla em que foram analisadas as características do perfil de cento e setenta e duas (172) escolas estaduais da região Oeste do estado do Paraná, por meio da análise dos questionários contextuais da Prova Brasil, que foram respondidos pelos diretores dessas escolas e cotejados com bibliografias especializadas.

Aqui, apresentamos as discussões em torno de dois aspectos do modelo de gestão adotado oficialmente pelo estado do Paraná para as escolas estaduais: gestão democrática participativa e gestão compartilhada. Ambos os aspectos são analisados considerando o contexto das políticas neoliberais em vigência.

De forma a tornar o texto mais didático, organizamos sua estrutura em três partes principais, sendo esta a introdução, com as reflexões a respeito do neoliberalismo e das políticas educacionais no Brasil, seguida do debate teórico sobre a gestão democrática e a gestão compartilhada, e, por fim, a abordagem da gestão nas escolas estaduais do Oeste do Paraná. 
No Brasil, o Banco Mundial propõe orientações em termos de educação desde a década de 1990, na tentativa de responder à crise estrutural do capitalismo, que teve início na década de 1970. Dessa forma, a educação passa a ser vista como uma possibilidade de formar trabalhadores que atendessem as necessidades do mercado em nível de conhecimento e técnica.

Na década de 1990, principalmente durante o mandato de Presidente da República de Fernando Henrique Cardoso (1995-2002), teve início o projeto de descentralização da gestão pública. A escola passou a ter a flexibilidade no planejamento e na gestão administrativa, e como obrigação apresentar o resultado do seu desempenho através da avaliação. Essa reforma se materializou a partir da Lei no 9.394/96, que propunha o fim do modelo burocrático de gestão para iniciar um novo modelo: o de gestão gerencialista baseado na lógica do Estado de caráter público não estatal.

Além das propostas para as políticas educacionais com o modelo gerencial baseado na "responsabilização por resultados, na competição administrativa por excelência, na responsabilização social e na auditoria de resultados" (BRESSER-PEREIRA, 2008 , p. 31), também houve o direcionamento para combater a pobreza promovendo a equidade e a eficiência. Nessa perspectiva, o Banco Mundial afirma que a educação promove o desenvolvimento social, garantindo oportunidades iguais a todos os cidadãos.

Essas estratégias utilizadas pelo Banco Mundial visam a inserir o Brasil, e outros países periféricos, no processo de globalização neoliberal, voltado para o crescimento econômico através do ideal de que o sistema educacional é determinante para diminuir a pobreza e manter a estabilidade política.

Em termo de gestão da escola, diretores e professores passam a ser pressionados pela comunidade escolar para melhorar os índices, desconsiderando-se, por vezes, a variabilidade de condições sociais e econômicas que envolvem as escolas.

Ao ampliar a participação da família e da comunidade pelo viés econômico, o Estado diminui sua responsabilidade sobre as condições de oferta da educação, permanecendo, quase que exclusivamente, no caráter prescritivo e regulador. Nessas condições, o Estado se estabelece como neutro uma vez que assegura o mínimo de condições sociais sem afetar o mercado.

A descentralização, que é considerada como "um instrumento de modernização gerencial da gestão pública, pela crença nas suas possibilidades de promover a eficácia e a eficiência dos serviços concernentes" (AZEVEDO, 2002, p. 54) contribui para legitimar a desresponsabilização do Estado, passando para as redes municipais, estaduais e escolas a responsabilidade pela qualidade.

Essa forma de organização gerencial traz à tona a articulação direta entre administração capitalista e as novas formas de organização do trabalho, da administração e da gestão direcionada à disciplina e ao controle do trabalho e da vida social dos trabalhadores, sendo que a educação é indispensável para a concretização desse modelo.

Dessa forma, reforça-se a ideia apresentada por Faleiros (1980), de que a política neoliberal camufla a verdadeira fase do sistema capitalista, que traz em seu meio a proteção do mercado e do capital criando a falsa impressão de um Estado defensor das camadas pobres. 
Nesse contexto, a legitimidade do Estado como provedor das políticas públicas passa a ser questionada, pois o Estado é visto como burocrático e ineficiente. As reformas estatais pregam o ideal de modernização a partir de modelos que buscam "introjetar na esfera pública as noções de eficiência, produtividade e racionalidade inerentes à lógica capitalista" (OLIVEIRA, 2000, p. 331).

De acordo com o CEPAL (1993, p. 27), as políticas educacionais devem estar interligadas, estabelecendo relações "entre os sistemas educacionais, de capacitação e de investigação científico-tecnológica entre si, bem como as relações destes com o sistema produtivo".

Na contramão da prescrição do CEPAL, Cunha (1991) defende que a gestão democrática da escola pública não deve ser entendida como uma forma de desobrigar o Estado de suas responsabilidades, pelo contrário:

[...] a gestão democrática da escola pública não deve ser entendida como uma forma de desobrigar o Estado de suas responsabilidades ou para criar uma escola de qualidade inferior para os carentes, respaldada na participação da comunidade, resultando no barateamento do currículo especialmente no ensino da leitura e da escrita (CUNHA, 1991, p. 395).

Já para Dourados (2006), gestão democrática da escola pública é muito mais que um sinônimo de administração, pois ela

[...] adquire uma dimensão muito maior do que a ideia de comando e qualidade total, presente no meio empresarial. Gerir democraticamente uma escola pública, uma organização social dotada de responsabilidades e particularidades, é construí-la coletivamente. Isto significa contrapor-se à centralização do poder na instituição escolar, bem como primar pela participação dos estudantes, funcionários, professores, pais e comunidade local na gestão do estabelecimento, na melhoria da qualidade do ensino e na luta pela superação da forma como a sociedade está organizada (DOURADOS, 2006, p. 30).

A participação da comunidade nos processos de gestão constitui-se no contraponto do instituído pelo modelo gerencial, desde que efetivamente coloque em evidência os parâmetros de gestão democrática na prática cotidiana das atividades administrativas e pedagógicas das instituições de ensino, como ferramenta de qualificação dos trabalhos desenvolvidos, e não simplesmente de regulação através de vigilância e fiscalização. Se, por um lado, a gestão democrática pensada além do sentido etimológico pode constituir-se como contraponto aos desdobramentos do gerencialismo neoliberal na educação, por outro lado o discurso da gestão participativa pode induzir a interpretações colaborativas ao espectro neoliberal do Estado mínimo.

\section{GESTÃO PARTICIPATIVA E GESTÃO COMPARTILHADA: ESPECTROS DO LIBERALISMO}


A gestão democrática se fundamenta na participação, na responsabilização, na autonomia de decisões pedagógicas, administrativas e financeiras, através da participação política da comunidade escolar, que está vinculada a um sistema descentralizado. Da mesma forma, a gestão compartilhada é uma prática política, mas que acaba por responsabilizar a escola pelo seu próprio fracasso. Sua marca principal é compartilhar o poder de manutenção à medida que o Estado se desresponsabiliza pelo provimento e amplia seu papel de fiscalizador.

Assim, a gestão compartilhada transfere a obrigação do Estado para a comunidade escolar, principalmente em relação à manutenção financeira, dando à escola autonomia para prover recursos financeiros por meio de ações com a comunidade escolar.

Nesse sentido, Nunes (1997) diferencia o significado das expressões Gestão Compartilhada e Gestão Democrática, estabelecendo que:

Falar em compartilhar a gestão, no sentido de repartir, participar ou tomar parte em, é substancialmente diferente da democratização da gestão como forma de controle da autoridade e dos poderes de decisão e execução. No primeiro sentido supõe-se alguém como proprietário da gestão (o governo ou o diretor, dependendo da instância) que magnanimamente reparte aquilo que é seu (uma vez que só se partilha aquilo que se tem). No segundo caso trata-se de controlar a quem dirige, entendendo-se que aquele que ocupa um cargo de direção o faz a serviço dos que o elegeram (ao menos nos regimes democráticos), é portanto um movimento da periferia para o centro, de baixo para cima, ao contrário da gestão compartilhada que é outorgada de cima para baixo (NUNES, 1997, p. 1).

Essa diferenciação entre gestão democrática e gestão compartilhada nos coloca diante de dois caminhos diferentes para o processo de gestão escolar. Por um lado, caminhamos em direção a participação e envolvimento da comunidade no processo educativo, desde sua organização teórica até as práticas mais simplórias e cotidianas, tanto em termos políticos como sociais e econômicos. Enquanto o outro se constitui em um processo de regulação verticalizada disfarçada de participação, onde se compartilham as responsabilidades e não a tomada de decisão.

Nesses termos, Lima, Prado e Shimamoto (2011) diferenciam gestão democrática de gestão compartilhada, sendo que as duas são práticas políticas. Assim definem a gestão democrática:

A gestão democrática é uma prática fundada em preceitos participativos e políticos. Ela não instrumentaliza a manutenção da escola, mas organiza a comunidade para buscar nos órgãos públicos a responsabilidade por sua manutenção. Constitui-se, portanto, nos fundamentos que tornam a escola vinculada a um sistema descentralizado, no qual haja autonomia de decisão financeira, pedagógica e administrativa. É, portanto, fundamental a existência 
SOLIGO, V.; SOLIGO, M. G. ESTRADA, A. A.

de mecanismos de participação da comunidade escolar que possibilitem a tomada de decisões coletivas para a construção do controle social. Isto, de modo algum implica em eximir o Estado da manutenção desta escola. Não significa, deste modo, que a escola seja a responsável pelo autofinanciamento de seus gastos (LIMA; PRADO; SHIMAMOTO, 2011, p. 7). resultado.

Já a gestão compartilhada entende a escola como responsável pelo seu

A gestão compartilhada também é uma prática política, porém contraditória em relação à prática democratizadora. Sua marca principal é a de responsabilizar a comunidade pelo fracasso escolar, pelo abandono da escola. Busca, assim, não compartilhar o poder de decisão, mas compartilhar o poder de manutenção (LIMA; PRADO; SHIMAMOTO, 2011, p. 7).

No Paraná, durante o mandato do governo de Álvaro Dias (1987-1990), a democratização da educação, no discurso oficial, ganha espaço em todas as dimensões, com destaque para a gestão com dois objetivos específicos, são eles:

Dar as escolas mais autonomia em relação à gestão, concentrando recursos na própria escola para que a administração do dia-a-dia seja desburocratizada e simplificada; e aproximar a escola de sua comunidade para garantir-lhe uma verdadeira inserção do tecido social e assegurar que a escola responda de maneira efetiva aquilo que a comunidade espera (PARANÁ, 1987, p. 6).

Esses objetivos, no discurso oficial, visavam a aproximar a escola da comunidade, ampliando a autonomia de gestão justificada pela necessidade de respostas mais rápidas e eficientes às demandas da comunidade. Entretanto, esse modelo de gestão esconde o ideal da desresponsabilização do Estado enquanto provedor do sistema, passando para as escolas, e consequentemente para seus gestores, a responsabilidade pela gestão financeira dos parcos recursos destinados à manutenção das escolas. Situação que, por vezes, leva os gestores e comunidade escolar a lançar mãos de artifícios financeiros como rifas, bingos e festas para arrecadar recursos complementares aos do Estado e poder fazer a manutenção básica das escolas.

No Paraná, a partir de 1995, o governador Jaime Lerner (1995-98) institui as diretrizes da "Gestão Escolar Compartilhada". Esse termo aparece no seu plano de ação para a educação como condição necessária para uma educação de excelência.

Essa ideia é reforçada no Plano de Governo (1995-1998), com o conceito "Gestão compartilhada" para a qualidade e excelência da educação.

De acordo com o Secretário da Educação da época, Ramiro Wahrhaftig,

A gestão compartilhada se constitui em condição imprescindível para promoção de excelência da educação, uma vez que a mesma está centrada no trabalho de pessoas que se devem organizar coletivamente em torno de objetivos comuns (PARANÁ, 1995, p. 5). 
Nesse contexto, o governo do Paraná implantou projetos financiados pelo Banco Mundial. Dentro dos projetos financiados, o de maior destaque foi o projeto Qualidade do Ensino Público do Paraná (PQE), assinado pelo governador Roberto Requião em 1995, já no final de seu mandato, e executado pelo governador Jaime Lerner (19961998). O seu plano de Ação baseou-se nos princípios norteadores do PQE, como nos apresenta Viriato et al. (2001): "Assim, se a gestão da escola for orientada pelos princípios administrativos, já testados em empresas privadas, a educação alcançará maior eficiência e equidade" (VIRIATO et al., 2001 p. 183).

Dessa maneira, a gestão compartilhada aparece na política educacional do plano de ação de Jaime Lerner:

Essa gestão orienta-se pela valorização da escola e de seus professores, de modo que assumam, no seu contexto, um trabalho dinâmico e eficaz que possibilite cada vez mais, a permanência do aluno com êxito no sistema, marcado também, por um sentido amplo de trabalho colegiado, envolvendo a comunidade externa à escola (PARANÁ, 1995, p. 5).

Essas estratégias de ação do governo do Paraná, influenciado pelos organismos internacionais, foram consideradas pelo Banco Mundial o modelo a ser seguido. E para a concretização da Gestão compartilhada, foram implantados programas entre a SEED e as escolas, são eles:

Fortalecimento dos Conselhos Escolares, Grêmios Estudantis e Associação de Pais e Mestres: - Aperfeiçoamento dos padrões de Gerenciamento Núcleo Do Regional de Educação (NRE) - Escola: Avaliação do sistema educacional (PARANÁ/SEED - Plano de Ação, 1995).

Com esse programa de Gestão Compartilhada, a responsabilidade pela educação foi além dos muros da escola, não somente os docentes e diretores escolares, mas os membros das APMs e a Comunidade escolar como um todo passaram a fazer parte dessa proposta.

Dessa forma, a presença do Banco Mundial na educação brasileira de forma geral, e paranaense de modo específico, é considerada necessária no modelo liberal para a reestruturação do capitalismo, principalmente nos países periféricos para o crescimento econômico. A gestão compartilhada passou a ser uma estratégia mercadológica que proporciona a competitividade entre as escolas e o gestor passou a ser visto como o responsável pelo sucesso e/ou pelo fracasso da escola, juntamente com a comunidade escolar, na medida em que o Estado se desresponsabiliza das obrigações enquanto mantenedor da educação. 
Diante da descentralização, o modelo de gestão escolar adotado nas políticas de governo no Paraná, o de gestão compartilhada, em que o Estado transfere as obrigações da manutenção e financiamento da educação, passando essa responsabilidade para a comunidade, como afirma Souza (2010, p. 210), é "uma concepção de 'Democracia Mínima Neoliberal'".

Nesses termos, considerando o contexto em que o modelo de gestão compartilhada foi implementado no estado do Paraná, pode-se afirmar que se trata de um modelo neoliberal que visa à diminuição do Estado através de sua desresponsabilização, ao mesmo tempo que amplia as responsabilidades da gestão escolar, de professores, alunos e comunidade.

Esse processo de descentralização administrativa vem acompanhado de três planos, como apresenta Viriato (2004):

[...] no plano político, a ênfase reside na participação e na democracia. No plano econômico, acena por recursos. No que se refere à qualidade do ensino, a ênfase recai na questão técnico-pedagógica e, por fim, o plano administrativo exige mais eficiência nos processos educacionais (VIRIATO, 2004, p. 47).

Em virtude disso, o que está acontecendo é uma desconcentração e não uma descentralização. Para Viriato (2004),

[...] o que está sendo implementado são políticas de desconcentração, uma vez que desconcentrar significa levar a execução para mais perto do lugar em que ocorre o ato educacional, assegurando, assim, os interesses do poder central, assegurando sua eficiência e eficácia (VIRIATO, 2004, p. 47).

Percebemos, assim, que a consolidação da gestão democrática, a autonomia da escola na elaboração do projeto pedagógico e o envolvimento da comunidade são princípios norteadores das políticas educacionais que se fizeram presentes nas ações de governo no Paraná.

\section{GESTÃO DAS ESCOLAS ESTADUAIS DA REGIÃO OESTE DO ESTADO DO PARANÁ}

O modelo oficial de gestão escolar adotado no Brasil é o democrático participativo. Entretanto, o efetivo exercício da participação exige mais do que conhecimentos de novos paradigmas de gestão.

O estilo democrático se assenta sobre a participação e sobre a tomada de decisão compartilhada, seguida de ações colaborativas, em que, em equipe, os membros da organização assumem responsabilidades conjuntas pelo desenvolvimento e realização de objetivos elevados (LUCK, 2010, p. 78). 
O perfil do diretor/gestor das escolas estaduais do estado do Paraná abre o debate sobre a gestão escolar, pois diante das características dos diretores podemos analisar como se dá a gestão das escolas. O primeiro elemento a ser analisado são os conselhos escolares como instrumentos de gestão. $O$ papel dos conselhos é discutido por Werle (2003), que ressalta a participação efetiva, afirmando que:

Os Conselhos não existem somente por definições legais, mas na medida em que as pessoas se dispõem a contribuir para o grupo, a (re) construir a própria escola pública [...] não existe um Conselho no vazio; ele é o que a comunidade escolar estabelecer construir e operacionalizar. Cada Conselho tem a face das relações que nele se estabelecem. Se forem relações de responsabilidade, de respeito, de construção, então, é assim que vão se constituir as funções deliberativas, consultivas e fiscalizadoras. Ao contrário, se são relações distanciadas, burocráticas, permeadas de argumentos, tais como: "já terminou o meu horário", "este é o meu terceiro turno de trabalho", "vamos terminar logo com isto", "não tenho nada a ver com isso", com que legitimidade o Conselho vai deliberar ou fiscalizar?! (WERLE, 2003, p. 60).

O Conselho Escolar (CE) é uma associação civil, uma entidade jurídica de direito privado sem fins lucrativos e vinculada à escola. Esse órgão colegiado e democrático permite a descentralização do poder, bem como a tomada de decisões sobre as questões administrativas e financeiras. Por meio dessa instância as decisões e discussões acontecem, e ela atua principalmente avaliando e fiscalizando o cumprimento do PPP, conforme Instrução 05/2019 SUED/SEED e a Orientação 17/2019 SUED/SEED - PR, acompanhando as ações pedagógicas e garantindo o cumprimento das normas da escola para a efetivação de melhoria da qualidade do processo educativo. Trata-se do órgão máximo dentro dos estabelecimentos de ensino da educação básica, sendo o diretor da escola o presidente do Conselho Escolar.

No gráfico abaixo, identificamos que muitas vezes o Conselho Escolar é considerado de pouca importância nas atividades diárias da escola.

Gráfico 1: Reunião com o Conselho Escolar

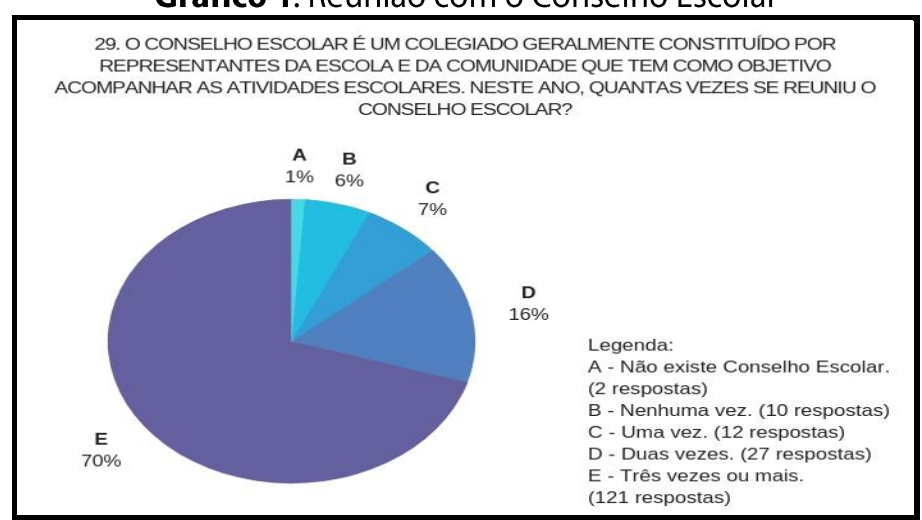

Fonte: Elaborado pelos autores. 
Considerando a importância desse órgão, por ter as funções deliberativas, consultiva, avaliativa e fiscalizadora, nem sempre as escolas dão destaque a essa instância. No caso dos questionários analisados, $7 \%$ não se reuniram durante o ano e em algumas escolas eles nem existem. Em $23 \%$ das escolas analisadas, os conselhos se reuniram uma ou duas vezes no ano, não caracterizando gestão democrática.

Os dados apresentados mostram que $14 \%$ das escolas pesquisadas estão em cumprimento com a legislação, possuindo Conselho Escolar, mas, em contrapartida, não há uma gestão democrática participativa quando se trata do Conselho Escolar, já que as atividades escolares acontecem diariamente e o Conselho Escolar não se faz presente. Quando se reúnem uma vez por ano o que transparece é que a reunião só existe para fazer uma prestação de contas. Em vez de estar articulado com o seu propósito, centrado no aluno, nos processos de ensino e aprendizagem, na qualidade de formação e no acompanhamento pedagógico da instituição, limita-se às questões administrativofinanceiras.

De acordo com as definições apresentadas nos escritos de Rocha (1984) e Libâneo (2004), a realização das reuniões pode indicar um perfil de gestão mais democrático ou menos democrático.

Assim, a implantação efetiva da gestão democrática deveria favorecer a participação, como demonstra Libâneo (2004):

A participação é o principal meio de assegurar a gestão democrática da escola, possibilitando o envolvimento de profissionais e usuários no processo de tomada de decisões e no funcionamento da organização escolar. Além disso, proporciona um melhor conhecimento dos objetos e metas, da estrutura organizacional e de sua dinâmica das relações da escola com a comunidade, e favorece uma aproximação maior entre direção, professores, alunos e pais (...) (LIBANEO, 2004, p. 102).

É relevante destacar que $82 \%$ das escolas possuem o Conselho Escolar composto pela representatividade de professores, funcionários, alunos, pais/responsáveis. Segundo a Instrução de 05/2019, a composição do Conselho Escolar deve ser formada com um percentual de no mínimo $60 \%$ e no máximo $80 \%$ de integrantes da comunidade escolar, e um percentual mínimo de $20 \%$ e no máximo $40 \%$ de integrantes da comunidade local. 


\section{Gráfico 2: Participação no Conselho Escolar}

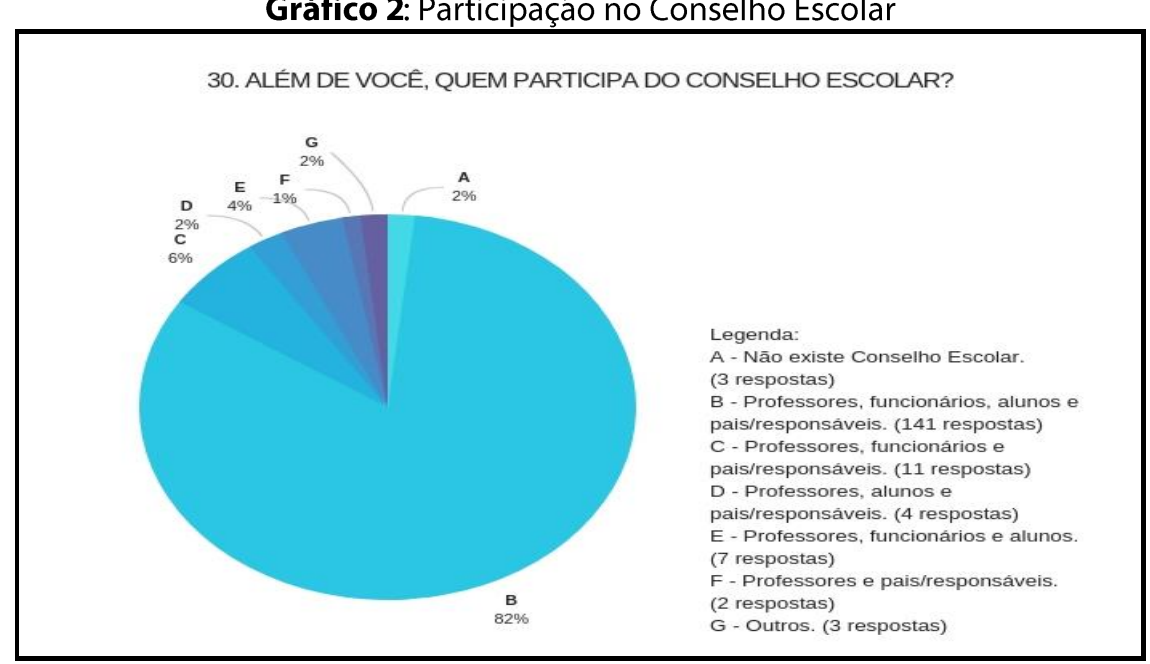

Fonte: Elaborado pelos autores.

Ainda assim, esse panorama não garante a presença de um CE democrático, como demonstrado no estudo de Souza (2006):

Os altos números de cada um dos segmentos na composição dos $C E$ poderiam demonstrar que o controle social sobre a ação institucional escolar está se ampliando. Isso pode ser verdadeiro, mas a simples identificação de que há representantes de segmentos diversos na composição dos conselhos não garante as formas mais democráticas de atuação do $C E$, pois a garantia da presença desses segmentos na composição do quadro de conselheiros não corresponde necessariamente às formas de participação, garantidas normativamente e/ou realizadas na prática (SOUZA, 2006, p. 243).

O Conselho Escolar é requisito essencial para a concretização de uma gestão democrática, com necessidade de participação efetiva da comunidade escolar nas decisões dos assuntos da escola, sendo um espaço permanente de debates, lutas e conquista por uma educação de qualidade.

Paro (1995) constatou que:

Embora a participação de pais e alunos nas decisões do Conselho da Escola nem sempre se faça da forma intensa que muitos poderiam esperar, o fato de ser aí o local onde se tomam ou se ratificam decisões de importância para o funcionamento da unidade escolar tem feito com que este órgão se torne a instância onde se explicitam e procuram resolver importantes contradições da vida escolar (PARO, 1995, p. 154). 
SOLIGO, V.; SOLIGO, M. G.; ESTRADA, A. A.

\section{Conforme o Estatuto do Conselho Escolar:}

O Conselho Escolar é um órgão colegiado, representativo da Comunidade Escolar, de natureza deliberativa, consultiva, avaliativa e fiscalizadora, sobre a organização e realização do trabalho pedagógico e administrativo da instituição escolar em conformidade com as políticas e diretrizes educacionais da SEED (PARANÁ, 2005, p. 09).

O Conselho Escolar visa, assim, a assegurar a qualidade do trabalho escolar nos segmentos administrativos, financeiros e pedagógicos.

O perfil da gestão escolar nas escolas estaduais pesquisadas é constituído pelo Conselho Escolar, ou seja, há predominância desta instituição nas escolas estaduais, caracterizando um perfil específico; mesmo que a pesquisa em voga não seja capaz de apresentar as formas de efetivação desses conselhos, a realização de reuniões de forma regular aponta uma participação dos diferentes setores da escola, podendo significar ou apresentar características de participação democrática.

O Conselho Escolar é um órgão de instância máxima no processo de tomada de decisão, de participação e de representação dos diversos segmentos da escola.

Conforme a Lei 9.394/96, a gestão democrática com seus mecanismos, entre eles o Conselho Escolar, estabelece no art. 14 que o Conselho deve ser formado por representantes da comunidade escolar, escolhido pelos seus pares através de votação.

Considerando a importância desse órgão colegiado, o processo de eleição do Conselho Escolar acontece de forma democrática, conforme o Estatuto estabelecido pelas Secretarias Estaduais de Educação. No Paraná, o mandato é de dois anos e a representatividade se dá conforme o exposto no artigo 17 do Estatuto do Conselho Escolar:

\footnotetext{
O Conselho Escolar, de acordo com o princípio da representatividade que abrange toda a comunidade escolar, terá assegurada na sua constituição a paridade (número igual de representantes por segmento) e a seguinte proporcionalidade: I - 50\% (cinquenta por cento) para a categoria profissionais da escola: professores, equipe pedagógica e funcionários; II - 50\% (cinquenta por cento) para a categoria comunidade atendida pela escola: alunos, pais de alunos e movimentos sociais organizados da comunidade (PARANÁ, 2005, p. 12).
}

No entanto, apesar da legislação, o quadro encontrado difere do escrito e mostra um colegiado incompleto, uma composição sem respeito à sua proporcionalidade, já que $17 \%$ do órgão estava composto sem a participação de todos os segmentos da comunidade escolar, conforme dados do Gráfico 2.

Um Conselho Escolar forte e comprometido dá suporte ao gestor nas tomadas de decisões. Essa formação de um Conselho Escolar ativo na participação da construção de uma escola de qualidade é muito importante.

Além do Conselho Escolar, a escola tem a Associação de Pais e Mestres (APMs). Essa associação é uma entidade jurídica de direito privado registrada em cartório, com um estatuto e sem fins lucrativos, que representa os interesses comuns dos profissionais e pais de alunos. O seu objetivo é colaborar com a gestão escolar, promovendo a integração 
da comunidade com a escola de forma democrática, impactando positivamente o aprendizado dos alunos e a qualidade da educação e auxiliando para que se cumpra os objetivos do projeto político pedagógico. Outro objetivo é apoiar financeiramente a direção da escola através da obtenção de recursos financeiros e de sua aplicação, já que a escola não tem autonomia de gerir de forma direta as verbas recebidas de recursos governamentais.

Os membros das APMs são eleitos em assembleia geral por meio de voto secreto para mandato de dois anos. Geralmente, elas são formadas por 23 membros, sendo três do conselho fiscal, nove da diretoria e onze do conselho deliberativo. A APM no sistema educacional brasileiro é uma exigência para o recebimento de verbas do Governo Federal do Programa Dinheiro Direto na Escola (PDDE) e na teoria é uma garantia de gestão democrática através da participação da comunidade escolar, conforme artigo 14 da Lei de Diretrizes e Bases da Educação (LDB 9394/96) e estratégia 19.4 do Plano Nacional de Educação (PNE).

As escolas têm autonomia para gerir recursos e a autonomia está ligada à participação da comunidade escolar nas decisões que contemplem a sua realidade. Entretanto, existe um descompasso entre as orientações das diretrizes. Por um lado, estimulam a autonomia, mas por outro lado normatizam a utilização dos recursos e estabelecem o tipo de autonomia que a escola pode ter, ou seja, a forma como o dinheiro pode ser gasto.

Essa descentralização não passa de uma devolução de encargos e responsabilidades sem devolução do poder, em que escolas recebem as determinações do Governo para a utilização dos recursos. Daí a necessidade de mudança, mudança esta por meio da participação de todos os segmentos da escola, da participação de uma gestão democrática e ativa na administração.

De acordo com Luckesi (2007, p. 15), "[U]ma escola é o que são os seus gestores, os seus educadores, os pais dos estudantes, os estudantes e a comunidade. A cara da escola decorre da ação conjunta de todos esses elementos", isto é, da participação efetiva e coletiva de todos visando a atender aos interesses da comunidade escolar para o alcance dos objetivos inseridos no projeto.

\section{CONSIDERAÇÕES FINAIS}

Diante das políticas neoliberais, a descentralização é considerada um instrumento de modernização gerencial da gestão pública pela crença nas suas possibilidades de promover a eficácia dos serviços concernentes. Essa forma de organização gerencial traz à tona a articulação direta entre administração capitalista e a gestão voltada para a disciplina e o controle do trabalho e da vida social dos trabalhadores, sendo que a educação é indispensável para a concretização desse modelo.

Entretanto, a gestão democrática da escola pública não deve ser entendida como uma forma de desobrigar o Estado de suas responsabilidades e a participação da comunidade nos processos de gestão constitui-se no contraponto do instituído pelo modelo gerencial, desde que efetivamente coloque em evidência os parâmetros de gestão democrática na prática cotidiana das atividades administrativas e pedagógicas das 
instituições de ensino. Nesse sentido, o papel do gestor numa escola pública é de incentivar a participação da comunidade escolar, buscando melhorias na escola, no ensino e nas relações pessoais.

Faz-se necessário destacar que a reforma gerencial do Estado iniciada na década de 1990 trouxe para o campo da educação novas estratégias educacionais de controle de resultados e racionalização dos recursos materiais e humanos sob o pressuposto da eficiência, com a racionalização e a flexibilização do trabalho. Entretanto, a gestão democrática, quando pensada para além do sentido etimológico, pode constituir-se como contraponto aos desdobramentos do gerencialismo neoliberal na educação. Já o discurso da gestão participativa pode induzir a interpretações colaborativas ao espectro neoliberal do Estado mínimo.

A gestão democrática se fundamenta na participação, na responsabilização, na autonomia de decisões pedagógicas, administrativas e financeiras, através da participação política da comunidade escolar, que está vinculada a um sistema descentralizado. Da mesma forma, a gestão compartilhada é uma prática política, mas que acaba por responsabilizar a escola pelo seu próprio fracasso. Sua marca principal é compartilhar o poder de manutenção à medida que o Estado se desresponsabiliza do provimento e amplia seu papel de fiscalizador. A gestão compartilhada transfere a obrigação do Estado para a comunidade escolar, principalmente em relação à manutenção financeira, dando à escola autonomia para prover recursos financeiros através de ações junto à comunidade escolar.

A gestão democrática e a gestão compartilhada nos colocam diante de dois caminhos diferentes para o processo de gestão escolar. Por um lado, caminhamos em direção a participação e envolvimento da comunidade no processo educativo, desde sua organização teórica até as práticas mais simplórias e cotidianas, tanto em termos políticos quanto em termos sociais e econômicos. Enquanto o outro se constitui em um processo de regulação verticalizada, disfarçada de participação, onde se compartilham as responsabilidades e não a tomada de decisão.

O modelo de gestão escolar adotado nas políticas de governo no Paraná é o de gestão compartilhada, em que o Estado transfere as obrigações da manutenção e do financiamento da educação, passando essa responsabilidade para a comunidade.

Nesses termos, considerando o contexto em que o modelo de gestão compartilhada foi implementado no estado do Paraná, pode-se afirmar que se trata de um modelo neoliberal que visa à diminuição do Estado através de sua desresponsabilização, ao mesmo tempo que amplia as responsabilidades da gestão escolar, de professores, alunos e comunidade.

Com esse programa de Gestão Compartilhada, a responsabilidade pela educação foi além dos muros da escola, não somente os docentes e diretores escolares, mas os membros das APMs e a Comunidade escolar como um todo passaram a fazer parte dessa proposta.

As escolas têm autonomia para gerir recursos e a autonomia está ligada à participação da comunidade escolar nas decisões que contemplem a sua realidade. Entretanto, existe um descompasso entre as orientações das diretrizes. Por um lado, elas estimulam a autonomia, mas por outro lado normatizam a utilização dos recursos e estabelecem o tipo de autonomia que a escola pode ter, ou seja, a forma como o dinheiro pode ser gasto. 
Os dados analisados na pesquisa apontam a existência da gestão democrática participativa nas escolas estaduais do Oeste Paranaense, entretanto a composição dos Conselhos Escolares e a frequência de reuniões implicam certa fragilidade na afirmação. Percebemos que mesmo com a existência de legislação e, por conseguinte, dos conselhos como órgãos deliberativos, os resultados indicam que, por vezes, os conselhos são apenas formas de legitimar os processos de desresponsabilização do Estado com um discurso de participação, pois a composição e a frequência das reuniões depõem contra a efetiva democratização da gestão enquanto instância participativa.

Artigo recebido em: 28/11/2019

Aprovado para publicação em: 17/02/2020

\section{PARTICIPATORY MANAGEMENT OF EDUCATION: NEOLIBERAL POLITICS OR ADMINISTRATIVE AUTONOMY?}

ABSTRACT: This study is part of a project where we discuss the profile of public school managers in western Paraná. We aim to present and debate the participatory management guidelines developed in the educational policies of the State of Paraná. The qualitative research based on literature review and data analysis from the Prova Brasil contextual questionnaires answered by the managers of state schools. As results we have notes about the reduction of the role of the State in education, decentralizing part of the financial management of schools while maintaining the centrality in the control of processes.

KEYWORDS: Participatory Management. Disclaimer. Neoliberalism. School management.

\section{GESTIÓN PARTICIPATIVA DE LA EDUCACIÓN: ¿POLÍTICA NEOLIBERAL O AUTONOMÍA ADMINISTRATIVA?}

RESUMEN: Este estudio es parte de un proyecto donde discutimos el perfil de los administradores de escuelas públicas en el oeste de Paraná. Nuestro objetivo es presentar y debatir las pautas de gestión participativa desarrolladas em las políticas educativas del Estado de Paraná. La investigación cualitativa basada em la revisión de la literatura y el análisis de datos de los cuestionarios contextuales de Prova Brasil respondidos por los gerentes de la educación, descentralizando parte de la gestión financeira de las escuelas manteniendo la centralidade em el control de los processos.

PALABRAS CLAVE: Gestión participativa. Descargo de responsabilidad. Neoliberalismo. Gestión escolar. 
SOLIGO, V.; SOLIGO, M. G. ESTRADA, A. A.

\section{REFERÊNCIAS}

AZEVEDO, J. M. L. de. Implicações da nova lógica de ação do Estado para a educação municipal. In: Educação e Sociedade, v. 23, n. 80, p. 49-71, set. 2002.

BRESSER-PEREIRA, L. C. Os primeiros passos da reforma gerencial do Estado de 1995. Trabalho escrito para ser publicado em livro organizado por Maria Ängela d'Incão. 2008. Disponível em: http://www.bresserpereira.org.br/papers /2008/08.13. Primeiros. PassosReformaGerencial.pdf. Acesso em: 06 jan. de 2009

CEPAL. UNESCO. MEC. Educação e conhecimento: eixo da transformação produtiva com equidade (uma visão sintética). 1993. Brasília: MEC/Inep, 1993. Disponível em: http://www.dominiopublico.gov.br/download/texto/me001682.pdf. Acesso em: 17 maio 2015.

CUNHA, L. A. Educação, estado e democracia no Brasil. São Paulo, Cortez/Niterói-RJ: Editora da Universidade Federal Fluminense/ Brasília-DF, LASCO do Brasil, 1991.

DOURADO, L. F. Gestão da educação escolar. Brasília: Universidade de Brasília, Centro de Educação a Distância, 2006.

FALEIROS, V. de P. A política social do estado capitalista: as funções da previdência e assistência sociais. São Paulo: Cortez Editora, 1980.

LIBANEO, J. C. Organização e Gestão da Escola. 5 ed. Goiânia: Alternativa, 2004.

LIMA, A. B. de; PRADO, J. C. do; SHIMAMOTO, S. V. de M. Gestão democrática, gestão gerencial e gestão compartilhada: novos nomes velhos rumos. Simpósio 2011. ANPAE. Disponível em:

http://anpae.org.br/simposio2011/cdrom2011/PDFs/trabalhosCompletos/comunicacoe sRelatos/0069.pdf. Acesso em: 03 abr. 2018.

LUCKESI, C. C. Gestão democrática da escola, ética e sala de aula. ABC Educatio, n. 64. São Paulo: Criarp, 2007.

NUNES, A. C. Gestão democrática ou compartilhada? Uma (não) tão simples questão de semântica. Conferência Estadual de Educação - APP Sindicato, Praia de Leste/PR, nov/1997.

OLIVEIRA, D. A. Educação básica: gestão do trabalho e da pobreza. Petrópolis, RJ: Vozes, 2000.

PARANÁ. Estatuto do Conselho Escolar. Secretaria de Estado da Educação. Superintendência de Educação. Coordenação de Apoio a Direção e Equipe Pedagógica. Curitiba - PR, 2005. 
PARANÁ. Instrução normativa conjunta nº 05/2019 - DEDUC/DPGE/SEED. Disponível em:

http://www.educacao.pr.gov.br/arquivos/File/instrucoes/2019/instrucao 052019 deduc dpgeseed.pdf Acesso em: 03 out. 2019.

PARANÁ. Orientação no 17/2019 - DEDUC/SEED. Disponível em: http://www.educacao.pr.gov.br/arquivos/File/orientacoes/2019/orientacao 172019 de ducseed.pdf. Acesso em: 14 ago. 2019.

PARANÁ. Projeto Pedagógico 1987-1990. Curitiba, 1987.

\section{PARANÁ/SEED. Plano de Ação da Secretaria de Estado da Educação do Paraná} (1995- 1998). Curitiba, 1995.

PARO, V. H. Por dentro da escola pública. São Paulo: Xamã, 1995.

SOUZA, A. R. de. Perfil da Gestão Escolar no Brasil. PUC/SP, 302 p. Tese de Doutorado em Educação (Programa de Pós-Graduação em Educação, Pontifícia Universidade Católica de São Paulo). São Paulo, 2006.

SOUZA, A. R. de; GOUVEIA, A. B. Diretores de escolas públicas: aspectos do trabalho docente. Educar em Revista, Curitiba, n. especial 1, p. 173-190, 2010.

VIRIATO, E. O. Descentralização e desconcentração como estratégia para redefinição do espaço público. In:LIMA, A. B. de (Org.). Estado, política educacionais e gestão compartilhada. São Paulo: Xamã, 2004.

VIRIATO, E. O. et al. A Gestão Democrática educacional na redefinição do papel do estado. Cascavel: Edunioeste, 2001.

WERLE, F. O. C. Conselhos Escolares: Implicações na gestão da Escola Básica. Rio de Janeiro: DP\&A, 2003.

\footnotetext{
VALDECIR SOLIGO: Doutor em Educação pela Universidade do Vale do Rio dos Sinos (UNISINOS); Mestre em Educação pela Universidade de Passo Fundo (UPF). Graduado em História e Pedagogia. Professor Titular do Programa de Pós Graduação em Educação da Universidade Estadual do Oeste Paraná (UNIOESTE) Campus de Cascavel e Professor Adjunto do Curso de Pedagogia UNIOESTE Campus de Cascavel, Pr.

Orcid: http://orcid.org/0000-0003-2618-009X

E-mail:valdecir_soligo@yahoo.com.br
} 
SOLIGO, V.; SOLIGO, M. G. ESTRADA, A. A.

Marinez Gasparin Soligo: Mestre em Educação pela Universidade Estadual do Oeste do Paraná. Graduada em Pedagogia e História (licenciatura). Professora da Rede Municipal de Educação.

Orcid: http://orcid.org/0000-0002-7561-6972

E-mail: marinezgasparin@yahoo.com.br

Adrian Alvarez Estrada: Doutor em Educação pela Universidade de São Paulo (2004). Atualmente é Professor da Universidade Estadual do Oeste do Paraná, onde é docente do Programa de Pós-Graduação em Educação e do Colegiado de Pedagogia.

Orcid: http://orcid.org/0000-0002-0980-8925

E-mail: adrianalvarez.estrada@gmail.com

Este periódico utiliza a licença Creative Commons Attribution 3.0, para periódicos de acesso aberto (Open Archives Iniciative - OAI). 